Revista Brasileira de Agricultura Irrigada v.9, no.5, p. 350 - 356, 2015

ISSN 1982-7679 (On-line)

Fortaleza, CE, INOVAGRI - http://www.inovagri.org.br

DOI: $10.7127 /$ rbai.v9n500350

Protocolo 350.15 - 20/07/2015 Aprovado em 11/09/2015

\title{
AVALIAÇÃO DOS TEORES DE Ca, Mg E S EM PIMENTÃO CULTIVADO COM ÁGUA RESIDUÁRIA DE DESSALINIZADORES VIA HIDROPONIA COM ADUBAÇÃO ORGÂNICA
}

Keivianne da Silva Lima Reges ${ }^{1}$, Thales Vinícius de Araújo Viana ${ }^{2}$, Francisco Sildemberny Souza dos Santos ${ }^{3}$, Geocleber Gomes de Sousa ${ }^{4}$, Caudivan Feitosa de Lacerda ${ }^{5}$, Gideone Gerson Souza Galdino ${ }^{6}$

\section{RESUMO}

O estudo teve o objetivo de avaliar os teores dos macronutrientes $\mathrm{Ca}$, Mg e S no cultivo do pimentão com água residuária de dessalinizadores via hidroponia com adubação orgânica na nutrição, devido a utilização de água residuária de dessalinizadores ser uma alternativa presente no semiárido, além disso, a salinidade do rejeito pode ser atenuada com a adição de matéria orgânica ao sistema de cultivo. A pesquisa foi conduzida em vasos com volume de $25 \mathrm{~L}$, na Unidade de Ensino, Pesquisa e Extensão do Instituto Federal de Educação, Ciência e Tecnologia do Ceará - IFCE, no município de Limoeiro do Norte, CE. O ensaio foi conduzido em cultivo hidropônico tipo aberto com os tratamentos distribuídos em delineamento de blocos casualizados em esquema fatorial $5 \times 4$, referentes a 5 concentrações de água salina $\left(0,5 ; 1,5 ; 3,0 ; 5,0\right.$ e 7,0 dS m$\left.{ }^{-1}\right)$ e 3 concentrações de biofertilizantes na solução nutritiva (B1 $=50 \%$ da recomendação; B2 $=100 \%$ da recomendação e B3 $=150 \%$ da recomendação) e mais uma testemunha adicional (solução mineral recomendada para hidroponia para a cultura do pimentão), com 4 repetições, totalizando 80 unidades experimentais, sendo utilizadas 3 plantas por parcela. Foram realizadas análises de tecido vegetal da folha, caule e raiz. Com base nos resultados obtidos pôde-se observar diferenças estatísticas nos teores de cálcio e enxofre. Com relação ao magnésio não foi observada diferença estatistica para folha e caule. O uso de água residuária de dessalinizadores via hidroponia com biofertilização com 100\% da recomendação supre as necessidades nutricionais das plantas de pimentão em Ca, $\mathrm{Mg}$ e S, por estarem dentro da faixa recomendada para a cultura.

Palavras-chave: Capsicum annum L., Macronutrientes secundários, salinidade.

\footnotetext{
${ }^{1}$ Mestre em Agronomia - Solos e Nutrição de Plantas pela UFC, Fortaleza - CE, Brasil. E-mail: kei.v@hotmail.com;

${ }^{2}$ Doutor em Irrigação e Drenagem - ESALQ, Professor do Departamento de Engenharia Agrícola, UFC, Fortaleza, CE, Brasil. E-mail thales@ufc.br;

${ }^{3}$ Doutorando em Engenharia Agricola - UFC, Professor, do IFCE Campus Limoeiro do Norte-CE, Brasil. E-mail: sildemberny@hotmail.com;

${ }^{4}$ Doutor em Engenharia Agricola - UFC Professor, da UNILAB - Instituto: Desenvolvimento Rural, Redenção - CE, Brasil. E-mail: sousag@unilab.edu.br;

${ }^{5}$ Doutor em Fisiologia Vegetal - UFV, Professor do Departamento de Engenharia Agrícola, UFC, Fortaleza, CE, Brasil. E-mail: cfeitosa@ufc.br;

${ }^{6}$ Graduando em Agronomia pelo IFCE Campus Limoeiro do Norte-CE, Brasil. E-mail: gideonegersons@gmail.com.
} 


\title{
EVALUATION OF CONTENTS OF CA, MG E S IN CHILI GROWING WITH REJECT DESALINATOR VIA HYDROPONICS WASTEWATER WITH ORGANIC FERTILIZER
}

\begin{abstract}
The study aimed to evaluate the content of macronutrients $\mathrm{Ca}, \mathrm{Mg}$ and $\mathrm{S}$ in chili cultivation with wastewater desalination plants via hydroponics with organic fertilization on nutrition, because the use of wastewater desalination plants as an alternative present in the semiarid also the salinity of the waste can be alleviated by the addition of organic matter to the culture system. The research was conducted in pots with volume of $25 \mathrm{~L}$, the Teaching Unit and Research of the Federal Institute of Education, Science and Technology Ceará - IFCE in Limoeiro do Norte County, CE. The trial was conducted in open type hydroponics with the treatments distributed in a randomized block design in a factorial $5 \times 4$, 5 relating to salt water concentrations $\left(0.5,1.5,3.0,5.0\right.$ and $\left.7.0 \mathrm{dS} \mathrm{m}^{-1}\right)$ and 3 biofertilizers concentrations in the nutrient solution (B1 $=50 \%$ of the recommendation; B2 $=100 \%$ of the recommendation and $\mathrm{B} 3=150 \%$ of the recommendation) and one additional witness (recommended mineral solution for hydroponics for Chili culture), with four repetitions, totaling 80 experimental units, being used three plants per plot. Plant tissue analyzes of leaf, stem and root were held. Based on the results it was observed statistical differences in calcium and sulfur. Regarding the magnesium was not observed statistical difference in the leaf and stem. The use of wastewater desalination plants via hydroponics with Biofertilization 100\% recommendation meets the nutritional needs of bell pepper plants in $\mathrm{Ca}, \mathrm{Mg}$ and $\mathrm{S}$, as they are within the recommended range for the culture.
\end{abstract}

Keywords: Capsicum annum L., secondary macronutrients, salinity.

\section{INTRODUÇÃO}

A salinidade em áreas irrigadas é consequência, muitas vezes, do uso de água de qualidade inadequada, associado ao manejo do sistema solo-água-planta, e à deficiência do sistema de drenagem. Qualquer que seja sua fonte, a água utilizada na irrigação sempre contém sais que, em geral, variam expressivamente em qualidade e quantidade.

O estresse salino inibe o crescimento das plantas em razão de reduzir o potencial osmótico da solução do solo, restringindo a disponibilidade de água e/ou pela acumulação excessiva de íons nos tecidos vegetais, podendo ocasionar toxicidade iônica, desequilíbrio nutricional, ou ambos; no entanto, o grau de severidade com que esses componentes influenciam o desenvolvimento das plantas é dependente de muitos fatores, como, espécie vegetal, cultivar, estádio fenológico, composição salina do meio, intensidade e duração do estresse e das condições edafoclimáticas e, ainda, manejo da irrigação (SILVA et al., 2003; GHEYI et al., 2005).

A disponibilidade e usos da água na região Nordeste do Brasil, particularmente na região semiárida, continuam a ser uma questão crucial no que concerne ao seu desenvolvimento. É fato que grandes esforços vêm sendo empreendidos com o objetivo de implantar infraestruturas capazes de disponibilizar água suficiente para garantir o abastecimento humano e animal e viabilizar a irrigação (CIRILO et al., 2010).

No Nordeste do Brasil, o nível de salinidade na água retirada de poços é alto em razão do tipo de solo. Em comunidades rurais isoladas e com dificuldade de acesso a água, os sistemas simplificados de dessalinizadores tornam a água potável.

O pimentão (Capsicum annum L.) é uma hortaliça de fruto, conhecida e consumida em todo o Brasil, utilizada in natura e processada. A área de pimentão cultivada anualmente no Brasil é em torno de 13 mil hectares, com 
produção próxima a 290 mil toneladas de frutos, sendo São Paulo, Minas Gerais, Bahia e Rio de Janeiro os principais estados produtores (MAROUELLI \& SILVA, 2012), e considerada moderadamente sensível à salinidade do solo (LIMA et al., 2012).

Buscando uma alternativa na reutilização de rejeitos dos dessalinizadores e produção de pimentões com adubação orgânica, o estudo possui o objetivo de avaliar os teores dos macronutrientes $\mathrm{Ca}, \mathrm{Mg}$ e $\mathrm{S}$ no uso de água residuária de dessalinizadores via hidroponia com adubação orgânica na nutrição.

\section{MATERIAL E MÉTODOS}

O estudo foi desenvolvido na Unidade de Ensino, Pesquisa e Extensão (UEPE) do Instituto Federal de Educação, Ciência e Tecnologia do Ceará (IFCE), localizada na Chapada do Apodi, em Limoeiro do Norte, CE.

O ensaio foi conduzido em cultivo hidropônico tipo aberto com os tratamentos distribuídos em delineamento de blocos casualizados em esquema fatorial $5 \times 4$, referentes as diferentes concentrações de água salina $\left(0,5 ; 1,5 ; 3,0 ; 5,0 ;\right.$ e $\left.7,5 \mathrm{dS} \mathrm{m}^{-1}\right)$ e 4 formas de aplicações de fertilizantes na solução nutritiva (biofertilizantes nas concentrações: $\mathrm{B} 1=50 \%$ da recomendação; B2 $=100 \%$ da recomendação e B3 $=150 \%$ da recomendação) e mais (solução mineral recomendada para hidroponia para a cultura do pimentão), com 4 repetições, totalizando 80 unidades experimentais, sendo utilizadas 3 plantas por parcela.

A variedade de pimentão utilizada foi o Yolo Wonder, as plantas foram transplantadas para ambiente protegido, com uma malha termo refletor (aluminet 50\%) para reduzir a temperatura no interior do ambiente após 30 dias da semeadura. O cultivo do pimentão foi realizado em vasos de plástico flexível com capacidade para 25 L, preenchidos com substrato (casca de arroz carbonizada). Em cada vaso foi transplantada uma muda de pimentão.

O tempo total de irrigação foi determinado pela capacidade de armazenamento do substrato sem que ocorresse a drenagem. As soluções constituídas foram fornecidas através de gotejadores com vazão de $2 \mathrm{~L} \mathrm{~h}^{-1}$. Uma vez

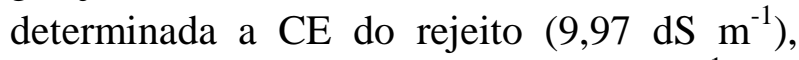
com a CE da água do local de $0,5 \mathrm{dS} \mathrm{m}^{-1} \mathrm{e}$, a partir da composição percentual do rejeito, chegou-se aos valores de CE dos tratamentos seguindo a seguinte equação.

$$
C E_{\text {FINAL }}=\frac{\left(C E_{R E J} \times \%_{R E J}\right)+\left(C E_{C A N A L} \times \%_{C A N A L}\right)}{100} \quad \text { Eq. } 01
$$

Onde:

CE FINAL_ Condutividade elétrica final da combinação das águas ( $\left.\mathrm{dS} \mathrm{m}^{-1}\right)$;

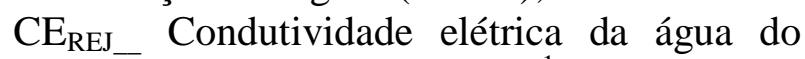
rejeito do dessalinizador $\left(\mathrm{dS} \mathrm{m}^{-1}\right)$;

$\%$ REJ__ Percentual da água do rejeito do dessalinizador;

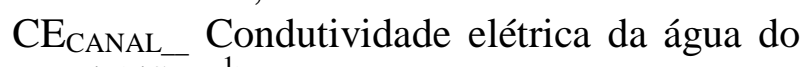
canal $\left(\mathrm{dS} \mathrm{m}{ }^{-1}\right)$;

\% CANAL_Percentual da água do canal.

$\mathrm{O}$ biofertilizante foi preparado por meio da fermentação anaeróbia contendo esterco fresco e água na proporção de 50\% (volume/volume $=\mathrm{v} / \mathrm{v}$ ), por um período de trinta dias, em recipiente plástico hermeticamente fechado, em sistema anaeróbico. Para garantir a uniformidade dos tratamentos, a adubação orgânica com biofertilizante teve início junto com a adubação mineral aos 35 DAT (dias após transplante).

A adubação mineral foi realizada manualmente com solução nutritiva indicada por Goto \& Rossi (1997) citados por Trani et al. (2011) para a cultura do pimentão. Na constituição da solução nutritiva foi seguida a recomendação proposta por Guimarães (2013), sendo $\mathrm{N}-\left(9,5\right.$ g planta $\left.^{-1}\right) ; \mathrm{P}-\left(7,5\right.$ g planta $\left.^{-1}\right)$ e K - (5 g planta $\left.{ }^{-1}\right)$.

Para a determinação do estado nutricional no final do ciclo, aos 75 DAT, as plantas foram fracionadas em folhas, caule e 
raiz. Os teores de $\mathrm{Ca}$ e $\mathrm{Mg}$ foram determinados por espectrofotometria e S pela determinação turbidimétrica do sulfato.

Os resultados foram submetidos à análise de variância e à análise de regressão, utilizando-se o programa computacional Sistema para Análise de Variância - SISVAR (FERREIRA, 2010), para um nível de significância de até $5 \%$ de probabilidade, pelo teste $\mathrm{F}$.

\section{RESULTADOS E DISCUSSÃO}

Para os teores de Ca houve um comportamento complexo em decorrência da instabilidade para se ajustar aos modelos matemáticos. Observa-se a presença do modelo quadrático para os teores desse nutriente no sistema radicular de todos os tratamentos, porém com coeficiente de rendimento baixo para as adubações com biofertilizante de 50, 100 e $150 \%$ da recomendação (Figura 1).
Os teores de Ca nas folhas, em função da salinidade e da adubação, variaram entre 16 e $25 \mathrm{~g} \mathrm{~kg}^{-1}$ que está dentro da faixa recomendada para a cultura do pimentão que varia de $10 \mathrm{a}$ $35 \mathrm{~g} \mathrm{~kg}^{-1}$ segundo a EMBRAPA (2009). Observa-se, quando se trata de partição, que o maior aporte deste nutriente encontra-se nas folhas e na raiz, sendo que as folhas é o principal órgão da planta, em termos de avaliação nutricional.

Relatos na literatura tem demonstrado que o aumento da salinidade pode induzir a deficiência de $\mathrm{Ca}$ nos diversos órgãos da planta (FARIAS, 2008). Desta forma, Ferreira et al. (2001) verificaram reduções nos teores de Ca nas folhas e em caules de goiabeira em função da aplicação de níveis crescentes de $\mathrm{NaCl}$. O cálcio é um elemento essencial para a integridade da membrana plasmática das células vegetais, e sua deficiência pode levar a perda da integridade da membrana, afetando desta forma a absorção de íons, principalmente o K (EPSTEIN \& BLOOM, 2006).

Figura 1: Regressão para teores de Ca na folha, caule e raiz da cultura do pimentão aos 75 DAT, cultivado com água residuária de dessalinizadores via hidroponia com adubação orgânica. Limoeiro do Norte, CE, 2014.

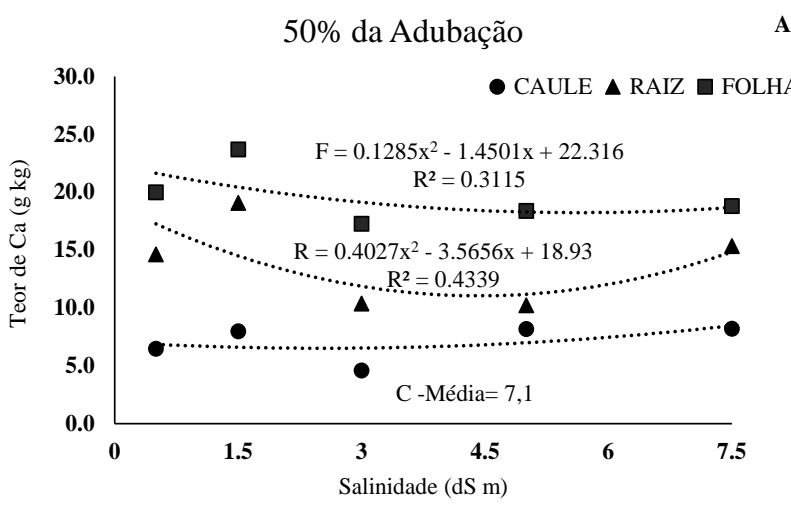

150\% da Adubação

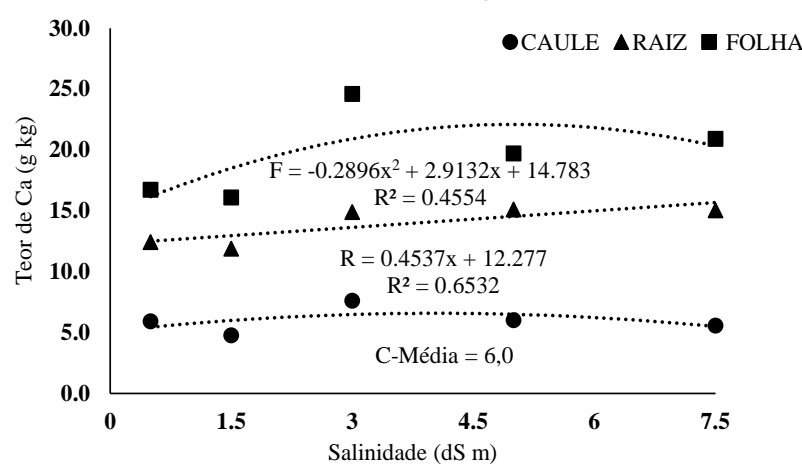

Silva et al. (2011), citando Sousa et al. (2007) relatam que a principal causa da

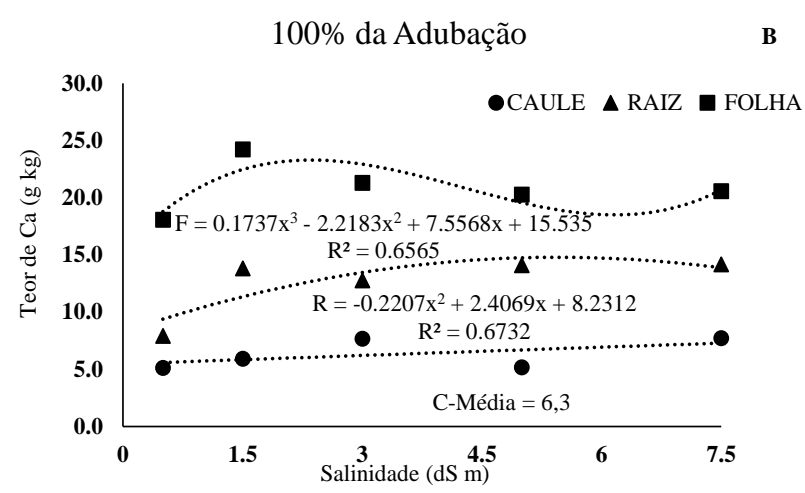

Adubação Mineral

D

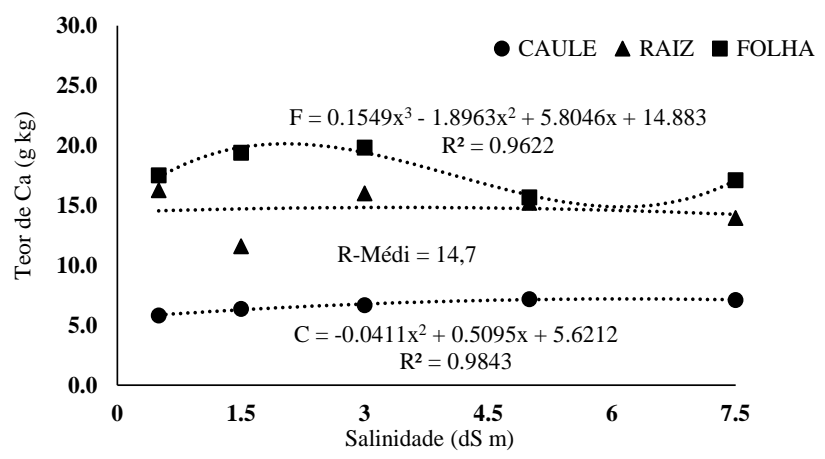

discrepância em relação aos efeitos da salinidade na aquisição de $\mathrm{Ca}$ pelas plantas 
pode estar relacionada às diferenças na composição da solução salina empregada no estudo. Os autores verificaram ainda que a presença do biofertilizante proporcionou menores teores de Ca nas folhas, e que o insumo não afetou os teores de nutriente nos caules.

Diferentemente do cálcio, os teores de magnésio nas plantas de pimentão apresentaram seus maiores valores no caule da planta deixando as folhas em segundo lugar em termo de partição de $\mathrm{Mg}$. Na figura 2, observa-se que o $\mathrm{Mg}$ no sistema radicular teve efeito polinomial quadrático para todos os tratamentos com redução do teor desse nutriente para as adubações com $100 \%$ da recomendação e mineral a partir da salinidade de 5 dS $\mathrm{m}^{-1}$.

Figura 2. Gráfico de regressão para teor de Mg na folha, caule e raiz da cultura do pimentão aos 75 DAT, em pimentão cultivado com água residuária de dessalinizadores via hidroponia com adubação orgânica. Limoeiro do Norte, CE, 2014.
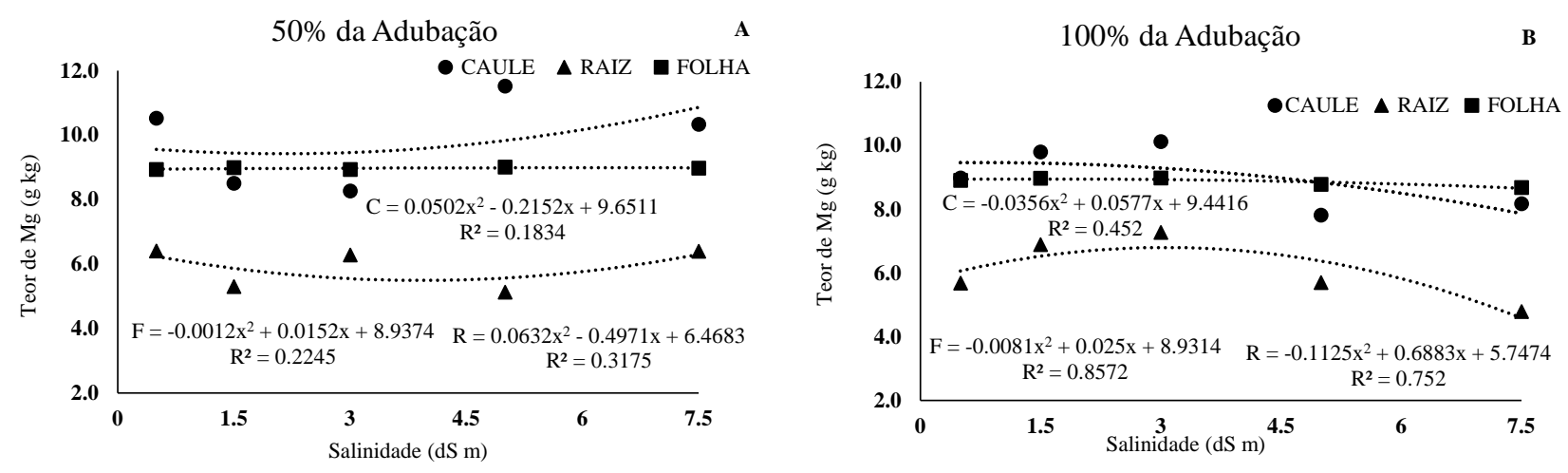

$150 \%$ da Adubação

C

Adubação Mineral

D
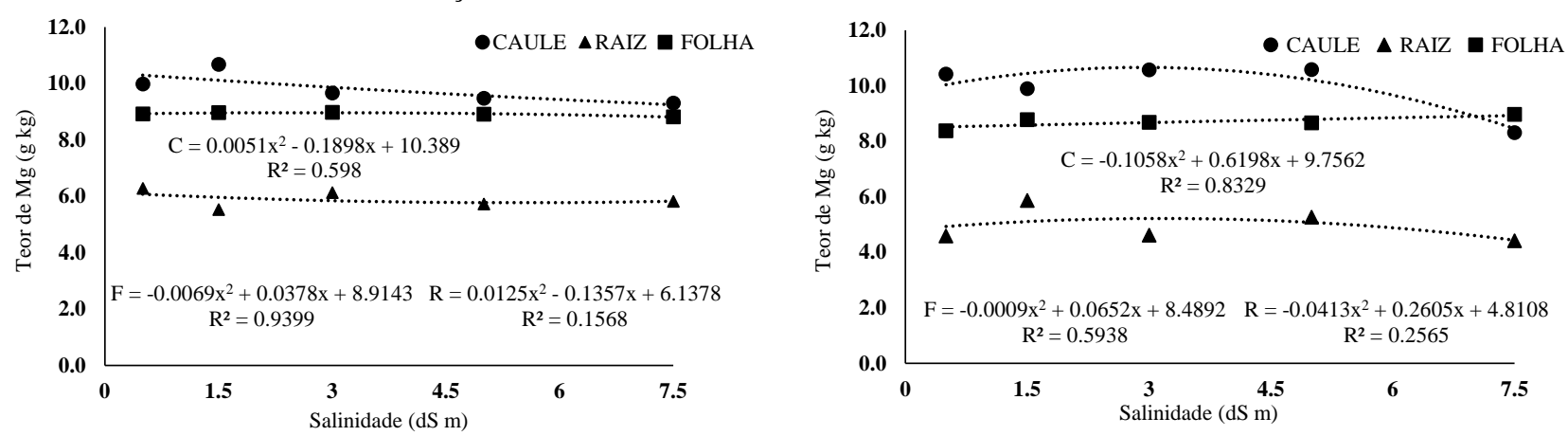

O enxofre contribui em funções da planta na estrutura celular; ajuda na produção de enzimas e vitaminas; necessário na formação da clorofila; participa no transporte fotossintético e respiratório de elétrons. Na figura 3 os teores de enxofre nas folhas em função da salinidade e da adubação variaram entre 3,0 a $6,0 \mathrm{mg} \mathrm{kg}^{-1}$, para as folhas, caule e para as raízes do pimentão, na

partição a superioridade foi nas folhas, isso se deve a função desse elemento ser prioritariamente nessa parte da planta. Os teores de enxofre encontrados na matéria seca de pimentão dessa pesquisa são marcadamente superiores aos $4 \mathrm{~g} \mathrm{~kg}^{-1}$ de enxofre em folhas de plantas também de pimentão nutricionalmente equilibradas em enxofre. (MALAVOLTA et al., 1997).

Figura 3. Gráfico de regressão para teor de $S$ na folha, caule e raiz da cultura do pimentão aos 75 DAT, em pimentão cultivado com água residuária de dessalinizadores via hidroponia com adubação orgânica. Limoeiro do Norte, CE, 2014. 


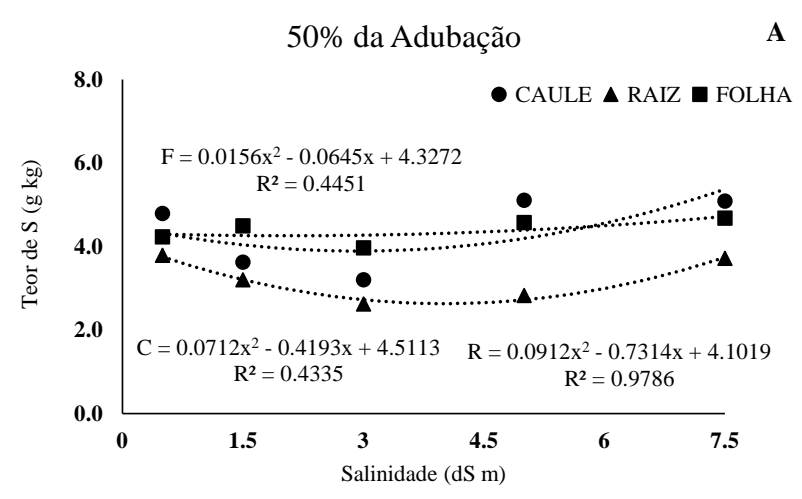

150\% da Adubação

C

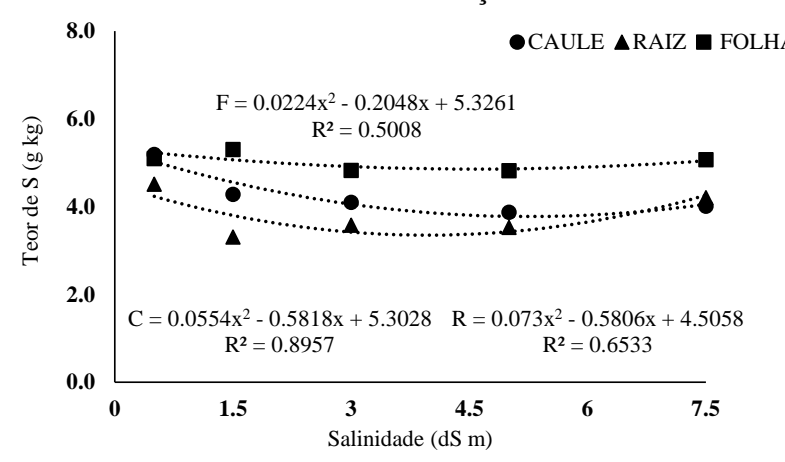

CONCLUSÕES

O uso de água residuária de dessalinizadores via hidroponia com biofertilização com $100 \%$ da recomendação supre as necessidades nutricionais das plantas de pimentão em $\mathrm{Ca}, \mathrm{Mg}$ e $\mathrm{S}$, por estarem dentro da faixa recomendada para a cultura.

\section{REFERÊNCIAS}

CIRILO, J. A.; MONTENEGRO, S. M. G. L.; CAMPOS, J. N. B. A questão da água no semiárido brasileiro. Disponivel em: < http://www.abc.org.br/IMG/pdf/doc-811.pdf>. Acesso em: mai/2015.

EMBRAPA. Manual de análises químicas de solos, plantas e fertilizantes. Embrapa Informação Tecnológica. $2^{a}$ edição revista e ampliada. 2009.

FARIAS, S. G. G. Estresse osmótico na germinação, crescimento e nutrição mineral de glicirídia (Gliricidia sepium (Jacq.). 61f.

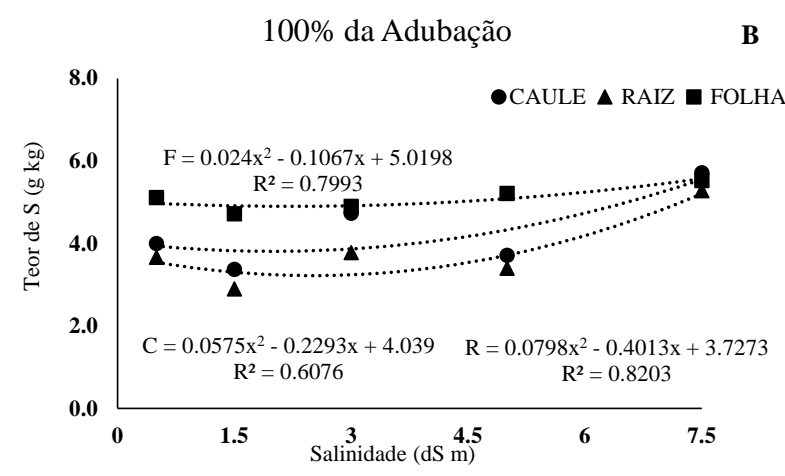

Adubação Mineral

D

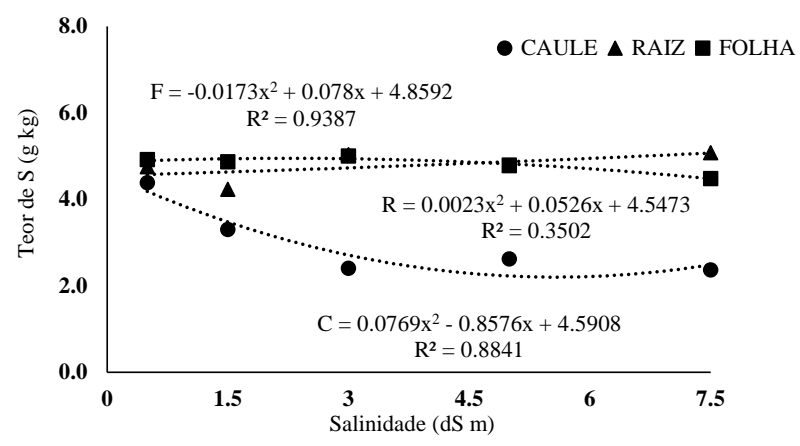

(Dissertação - Mestrado) Universidade Federal de Campina Grande. Brasil, 2008.

FERREIRA, Raimundo Gonçalves; TÁVORA, F. J. A. F.; HERNANDEZ, Fernando Felipe Ferreyra. Distribuição da matéria seca e composição química das raízes, caule e folhas de goiabeira submetida a estresse salino. Pesquisa Agropecuária Brasileira, v. 36, n. 1, p. 79-88, 2001.

GHEYI, H. R.; CORREIA, K. G.; FERNANDES, P. D. Salinidade do solo e crescimento e desenvolvimento das plantas. In: NOGUEIRA, R. J. C.; ARAÚJO, E. L.; Willadino, L. G.; CAVALCANTE, U. M. T. (ed.). Estresses ambientais: Danos e benefícios em plantas. Recife: UFRPE, 2005, p.138 -148.

LIMA, BL de C. et al.; I. B. do Nascimento; J. F. de Medeiros; I. J. S. Procópio; D. P. de Moraes; D. de H. Campelo. Influência da salinidade no desenvolvimento inicial do pimentão cultivado em dois tipos de solos. 
Inovagre Internacional Meeting \& Winotec,

Fortaleza, CE. 2012.

MALAVOLTA, E.; VITTI, G. C.; OLIVEIRA, S. A. Avaliação do estado nutricional das plantas: princípios e aplicações. 2. ed. Piracicaba: Associação Brasileira para a Pesquisa da Potassa e do Fosfato, 1997.

MOURELLI, W. A. \& SILVA, W. L. C. Irrigação na cultura do pimentão. Circular técnico 101. Brasília, DF. Março, 2012.
SILVA, F. L. B.; LACERDA, C. F.; SOUSA, G. G.; NEVES, A. L. R.; SILVA, G. L.; SOUSA, C. H. C. Interação entre salinidade e biofertilizante bovino na cultura do feijão-decorda. Revista Brasileira de Engenharia Agrícola e Ambiental, v.15, n.04, p.383-389, 2011.

SOUSA, R. A.; Lacerda, C. F. de; Filho, J. A.; Hernandez, F. F. F. Crescimento e nutrição mineral do feijão-de-corda em função da salinidade e da composição iônica da água de irrigação. Revista Brasileira de Ciências Agrárias, v.2, n.1 p.75-82. 2007. 